\title{
Culture of Chicken Embryos Obtained from the Anterior Region of the Magnum of the Oviduct after Removing a Thin Layer of Dense Albumen Capsule from the Ovum
}

\author{
Mitsuru Naito ${ }^{1}$, Akiko Sano ${ }^{1}$, Takaharu Kawashima ${ }^{1,2}$, Hiroyuki Nakamichi ${ }^{1,3}$, \\ Takashi Harumi $^{1}$, Yuko Matsubara ${ }^{1}$ and Takashi Kuwana ${ }^{2}$ \\ ${ }^{1}$ Animal Genetic Engineering Laboratory, National Institute of Agrobiological Sciences, \\ Tsukuba, Ibaraki 305-8602, Japan \\ ${ }^{2}$ Laboratory of Intellectual Fundamentals for Environmental Studies, National Institute \\ for Environmental Studies, Tsukuba, Ibaraki 305-8506, Japan \\ ${ }^{3}$ Graduate School of Agriculture, Ibaraki University, Ami-machi, Ibaraki 300-0393, Japan
}

Fertilised ova, obtained from the anterior region of the magnum of the oviduct 60$80 \mathrm{~min}$ after the preceding egg had been laid, were cultured in vitro with dense albumen adjusted to $\mathrm{pH} 7.0$ after removing a thin layer of dense albumen capsule surrounding the ovum. The ova were then cultured in recipient eggshells until hatching. Of 80 cultured embryos, about half developed to the blastoderm stage, $25 \%$ survived to day 4 of incubation, and $7.5 \%$ survived to hatching. The embryo culture technique developed in this study enables precise manipulation of the germinal disc just after ovulation.

Key words : chicken embryo culture, dense albumen, embryo manipulation, fertilised ovum

\section{Introduction}

Fertilisation in chickens takes place in the infundibulum of the oviduct within 15 minutes after ovulation (Olsen and Neher, 1948). The whole process of fertilisation still remains unknown partly because several spermatozoa penetrate the inner perivitelline layer and enter the germinal disc, namely, polyspermy (Perry, 1987). The development of in vitro fertilisation techniques in chickens will make it possible to study the precise mechanism of fertilisation. Also, the techniques can be applicable for proliferation of endangered avian species in which only small numbers of spermatozoa are available. For the development of the in vitro manipulated embryos of newly ovulated ova, it is preferable to culture the embryos in vitro through to hatching.

Hatching the culturing chicken embryos was achieved using surrogate eggshells as culture vessels. Rowlett and Simkiss (1987) reported that 3-day incubated chicken embryos could be cultured to hatching using turkey eggshells. Then, Perry (1988) devised a three-step culture method for the chicken embryos from the single-cell stage

Received : December 6, 2004, Accepted : December 24, 2004

Correspondence to : Dr. Mitsuru Naito, Animal Genetic Engineering Laboratory, National Institute of Agrobiological Sciences, Tsukuba, Ibaraki 305-8602, Japan

Tel : +81-29-838-8622 Fax : +81-29-838-8606 E-mail : mnaito@affrc.go.jp 
obtained from the posterior region of the magnum to hatching using glass jars and chicken eggshells. In this method (system I), the germinal disc was covered with a dense albumen capsule. This embryo culture system was applied for culturing earlycleavage stage embryos (stage II, Eyal-Giladi and Kochav, 1976) obtained from the anterior region of the uterus by hormonal treatment (Naito and Perry, 1989). Furthermore, Naito et al. (1990 a) found that a dense albumen capsule surrounding the ovum was not essential for the normal development of the embryos from stage X (Eyal-Giladi and Kochav, 1976) onward and could be substituted by thin albumen. Based on this discovery, they devised a modified method for culturing chicken embryos from the single-cell stage to hatching, that is, removing the dense albumen capsule from the stage $\mathrm{X}$ onward (systems II and III), and achieved a high rate of hatching (34.4\%). After that, Naito et al. (1995) succeeded in culturing the chicken embryos obtained from the anterior region of the magnum to hatching. In this case, a thin layer of dense albumen capsule was formed around the ovum, and the germinal disc region of the ovum was covered with gauze. The presence of this dense albumen capsule, even as a thin layer, usually interferes with precise manipulation of the germinal disc, such as sperm microinjection. It is therefore necessary to expose the germinal disc region of the ovum by removing the dense albumen. But, so far, no embryo culture method was devised for the fertilised ovum without a dense albumen capsule around the yolk.

The present study was conducted to develop a novel culture method for chicken embryos obtained from the anterior region of the magnum after removing a thin layer of dense albumen capsule from the ovum.

\section{Materials and Methods}

White Leghorn hens were artificially inseminated. Fertilised ova were obtained from the anterior region of the magnum 60-80 min after the preceding egg had been laid (40-60 min after ovulation, Naito et al., 1990 b). A thin layer of dense albumen capsule formed around the ovum was removed and the ovum was placed in a glass vessel (inside diameter $35 \mathrm{~mm}$, height $55 \mathrm{~mm}$ ). The dense albumen collected from freshly laid eggs was then poured over the ovum and filled the glass vessel. The $\mathrm{pH}$ of the dense albumen was adjusted to 7.0 by stirring in an atmosphere of $\mathrm{CO}_{2}$. The opening of the glass vessel was covered with Parafilm (American National Can, Chicago, U.S.A.) and secured with a plastic lid (Fig. 1). The fertilised ova were cultured for $26 \mathrm{~h}$ at $41.5^{\circ} \mathrm{C}$ with rocking through an angle of 90 degrees every hour. Then, the fertilised ova (yolk) were transferred to small recipient eggshells, filled with thin albumen, covered with cling film and secured with plastic rings and elastic bands (system II, Perry, 1988 ; Naito et al., $1990 \mathrm{a}$ ). The reconstituted eggs were incubated for 3 days at $38^{\circ} \mathrm{C}$. The contents of the reconstituted eggs were then transferred to large recipient eggshells, covered with cling film (system III, Rowlett and Simkiss, 1987 ; Perry, 1988 ; Naito et al., 1990 a) and incubated at $37.8^{\circ} \mathrm{C}$ until hatching.

All animals received humane care as outlined in the Guide for the Care and Use of Experimental Animals (National Institute of Agrobiological Sciences Animal Care Committee). 


\section{Results}

At the beginning of the culture, the ovum was placed at the bottom of the glass vessel (Fig. 1). The ovum was then floating gradually, and positioned at the middle to top of the glass vessel after 26 hours of incubation. The $\mathrm{pH}$ of the dense albumen increased from 7.0 at the beginning to 8.0 at the end of the culture. About half of the cultured embryos showed an opaque ring surrounding a semi-transparent area. Viability of the cultured embryos at day 4 of incubation was $25.0 \%(20 / 80)$ and finally $7.5 \%$ $(6 / 80)$ of the cultured embryos hatched (Table 1$)$. These hatched chicks were healthy, reached sexual maturity, and showed normal reproductive performance.

\section{Discussion}

The dense albumen is secreted around the ovum in the magnum of the hen's oviduct, and the $\mathrm{pH}$ of the albumen is stable at 7.15-7.4 by the $\mathrm{CO}_{2}$-rich environment

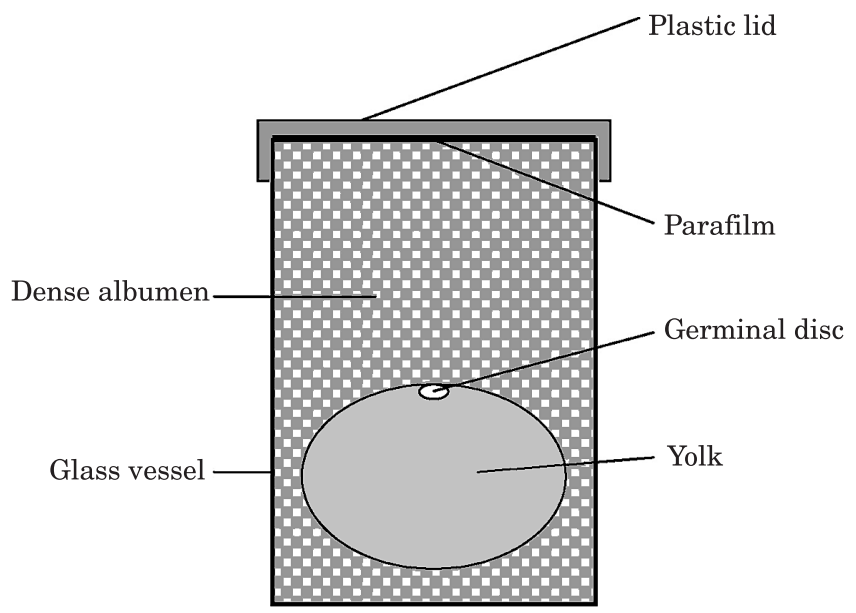

Fig. 1. Culture of chicken embryo obtained from the anterior region of the magnum of the oviduct to blastodermal stage. The fertilised ovum is cultured in a glass vessel with dense albumen adjusted the $\mathrm{pH} 7.0$ after removing a thin layer of dense albumen capsule surrounding the ovum.

Table 1. Development and hatching embryos of cultured fertilised ova obtained from the anterior region of the magnum of the oviduct after removing a thin layer of dense albumen capsule surrounding the ovum

\begin{tabular}{ccc}
\hline \hline $\begin{array}{c}\text { Number of embryos } \\
\text { treated }\end{array}$ & $\begin{array}{c}\text { Number (\%) of embryos } \\
\text { survived at day } \\
\text { of incubation }\end{array}$ & $\begin{array}{c}\text { Number (\%) of } \\
\text { embryos hatched }\end{array}$ \\
\hline 80 & 20 & 6 \\
$(25.0 \%)$ & $(7.5 \%)$ \\
\hline
\end{tabular}


inside the oviduct (Perry and Mather, 1991). During this period, the ovum is covered with the secreted dense albumen which maintained the $\mathrm{pH}$ in the oviductal phase, and the embryo develops normally in the oviduct under this environment. When the dense albumen capsule was removed from the fertilised ovum obtained from the anterior or posterior region of the magnum, the embryos did not develop further (Naito, unpublished) even when cultured by the method of Perry (1988) or Naito et al. (1995). It is, therefore, suggested that the presence of the dense albumen capsule surrounding the ovum plays an important role in the normal development of the embryos in the oviductal phase.

In the present experiment, the fertilised ovum obtained from the anterior region of the magnum was cultured in a similar environment to the oviductal conditions after removing a thin layer of dense albumen capsule around the ovum, namely, the germinal disc area of the ovum contacts to the dense albumen adjusted to $\mathrm{pH}$ 7.0. Usually, the ovum (yolk) floats in the dense albumen with the germinal disc positioned on top of the ovum due to the difference in the specific gravities of the yolk and the dense albumen, and also the difference in the specific gravities of the germinal disc area of the ovum (animal sphere) and the opposite side. In order to avoid floating the ovum in the dense albumen, the appropriate size of glass vessel was used and the mass of the dense albumen was poured over the ovum. The opening of the glass vessel was sealed with Parafilm and a plastic lid to minimise loss of $\mathrm{CO}_{2}$ and maintain the $\mathrm{pH}$ of the dense albumen in the oviductal phase. The rocking was effective in avoiding adhesion of the yolk membrane to the glass vessel. Although the $\mathrm{pH}$ of the dense albumen rose to 8.0 at the end of the first 26 hours in culture, about half of the embryos developed to the blastoderm stage showing an opaque ring of the blastoderm consisting of the area opaca and the area pellucida. The embryos were then cultured in system II, and $25.0 \%$ of the embryos developed to stage 18 (Hamburger and Hamilton, 1951). This viability was lower than the $46.3 \%$ reported by Naito et al. (1995) in which the fertilised ovum was cultured with a thin layer of dense albumen and the germinal disc area of the ovum was covered with gauze. Also, this viability was lower compared with that of $76.0 \%$ reported by Perry (1988) or $81.3 \%$ reported by Naito et al. (1990a) in which the fertilised ovum was obtained from the posterior region of the magnum and the ovum was covered with a thick layer of dense albumen. These results suggest that the amount and the $\mathrm{pH}$ of dense albumen surrounding the ovum affect the survival and normal development of the embryos in the oviductal phase.

The hatching rate of the embryos cultured in vitro (system I) and in surrogate eggshells (systems II and III) was 7.5\% in the present experiment. This hatching rate was lower than that of $19.5 \%$ reported by Naito et al. (1995). The difference in the hatching rate between the two culture methods mainly seems to reflect the difference in viability in the first 26 hours in culture. For further improvement of the viability and hatching rate of newly ovulated embryos cultured in vitro without the dense albumen capsule surrounding the ovum, it is necessary to culture the embryos in a high $\mathrm{CO}_{2}$ atmosphere (Ono et al., 1996) during the first 26 hours of incubation to maintain the $\mathrm{pH}$ of the dense albumen throughout the oviductal phase. Furthermore, oxygen supply into 
the incubator (Kamihira et al., 1998) during the last phase of the incubation period could improve the hatchability of cultured embryos.

The embryo culture technique developed in this study enables precise manipulation of the germinal disc just after ovulation, and can be used to study the mechanism of fertilisation, production of viable offspring by intra-cytoplasmic sperm injection, production of somatic cell-derived offspring by nuclear transfer, and production of transgenic chickens by DNA microinjection.

\section{Acknowledgement}

The authors would like to thank the staff of the Poultry Management Section of the National Institute of Livestock and Grassland Science for taking care of the birds. This study was supported by the Special Coordination Fund from the Ministry of Education, Culture, Sports, Science and Technology of the Japanese Government and a Grant-inAid (No. 16380193) from the Japan Society for the Promotion of Science. Part of this study was funded by the Cooperative System for Supporting Priority Research.

\section{References}

Eyal-Giladi $\mathrm{H}$ and Kochav S. From cleavage to primitive streak formation : A complementary normal table and a new look at the first stages of the development of the chick I. General morphology. Developmental Biology, 49 : 321-337. 1976.

Hamburger V and Hamilton HL. A series of normal stages in the development of the chick embryo. Journal of Morphology, $8:$ 49-92. 1951.

Kamihira M, Oguchi S, Tachibana A, Kitagawa Y and Iijima S. Improved hatching for in vitro quail embryo culture using surrogate eggshell and artificial vessel. Development Growth and Differentiation, $40:$ 449-455. 1998.

Naito M and Perry MM. Development in culture of the chick embryo from cleavage to hatch. British Poultry Science, $30: 251-256.1989$.

Naito M, Nirasawa K and Oishi T. Development in culture of the chick embryo from fertilized ovum to hatching. Journal of Experimental Zoology, 254 : 322-326. 1990 a.

Naito M, Nirasawa K and Oishi T. Duration of egg formation in hens selected for increased rate of lay under $23 \mathrm{~h}$ and $24 \mathrm{~h}$ light-dark cycles. British Poultry Science, $31: 371-375.1990 \mathrm{~b}$.

Naito M, Nirasawa $\mathrm{K}$ and Oishi T. An in vitro culture method for chick embryos obtained from the anterior portion of the magnum of oviduct. British Poultry Science, $36: 161-164.1995$.

Olsen MW and Neher BH. The site of fertilization in the domestic fowl. Journal of Experimental Zoology, 109 : 355-366. 1948.

Ono T, Murakami T, Tanabe Y, Mizutani M, Mochii M and Eguchi G. Culture of naked quail (Coturnix coturnix japonica) ova in vitro for avian transgenesis : culture from the single-cell stage to hatching with $\mathrm{pH}$-adjusted chicken thick albumen. Comparative Biochemistry and Physiology, 113A : 287-292. 1996.

Perry MM. Nuclear events from fertilisation to early cleavage stages in the domestic fowl (Gallus domesticus). Journal of Anatomy, $150: 99-109.1987$.

Perry MM. A complete culture system for the chick embryo. Nature, $331: 70-72$. 1988.

Perry MM and Mather CM. Satisfying the needs of the chick embryo in culture, with emphasis on the first week of development, in : Avian Incubation (Tullet SG. ed.). pp. 91-106. Butterworth-Heinemann. London. 1991.

Rowlett K and Simkiss K. Explanted embryo culture : in vitro and in ovo techniques for domestic fowl. British Poultry Science, 28 : 91-101. 1987. 